\title{
The effects of constructivist learning environments: a commentary
}

\author{
Remy M. J. P. Rikers • Tamara van Gog • Fred Paas
}

Received: 14 August 2008/Accepted: 17 August 2008/Published online: 3 September 2008

(C) The Author(s) 2008. This article is published with open access at Springerlink.com

\begin{abstract}
This special issue on the effects of constructivist learning environments is based on a symposium organized during the last annual meeting of the American Educational Research Association in Chicago. The studies in this issue not only provide an overview of the multitude of forms a constructivist learning environment can take, they also provide the reader with an overview of recent advances in this domain of research. The present discussion article provides a critical reflection on the studies in this special issue and tries to identify their prospects and limitations.
\end{abstract}

Keywords Constructivism $\cdot$ Learning environments

Creating an effective constructivist learning environment for students is certainly not a trivial task. Things become even more difficult because we have no clear, definitive idea of what constructivist learning environments are, or what they should look like (Harris and Alexander 1998). This matter is explicitly addressed by Loyens and Gijbels in their introduction to this special issue on the effects of constructivist learning environments. We may agree upon a couple of general characteristics of constructivist learning environments. However, what really counts is how these characteristics have been translated into the learning environment and how effective they are in terms of mediating knowledge and skills. The papers in this special issue provide some samples of the many forms a constructivist learning environment can take and of the effects of these environments on students' knowledge and skills. In a random order this discussion article will provide a critical reflection on the studies in this special issue and it tries to identify their prospects and limitations.

\footnotetext{
R. M. J. P. Rikers ( $₫)$

Department of Psychology, Erasmus University Rotterdam, Burgemeester Oudlaan 50, 3062, PA, Rotterdam, The Netherlands

e-mail: Rikers@fsw.eur.nl

T. van Gog $\cdot$ F. Paas

Open University of the Netherlands (OUNL/OTEC), Heerlen, The Netherlands
} 
The computer and the Internet have become increasingly important in modern education and they will without any doubt become even more important in the future. The study by Hmelo-Silver, Chernobilsky, and Jordan (this issue) is, however, the only study in this special issue that explicitly involves the use of new technology in education. In a computer-mediated problem-based learning environment, Hmelo-Silver and colleagues attempt to capture the dynamic nature of the collaborative learning processes. By visually representing the chronology of discourse and tool use (such as a personal notebook, electronic whiteboard) associated with an activity, they make it possible to get a better overview of the collaborative learning processes in a computer supported learning (CSCL) environment. Although the presented approach called CORDTRA (Chronologically-Ordered Representations of Discourse and Tool-Related Activity) is in our view very promising, the major challenge for future research using this technique is to establish a firm link between the outcome measures and the (constructivist) theoretical framework. That is, developing an instrument that is better able to capture the processes of a computer supported learning environment, and showing differences between an effective and a less effective group of students, becomes even more meaningful if they are interpreted in light of the theoretical framework. Obviously, this is easier said than done, because many activities in a problembased learning environment cannot be indisputably linked to the framework.

An important goal of constructivist learning environments is to engage students in deep and meaningful learning. Inspired by a previous study by Gijbels and Dochy (2006), Baeten and colleagues (this issue) try to achieve this goal using an alternative form of assessment. They investigated the influence of students' approaches to learning and assessment preferences in a portfolio-based learning environment. Using a pretest/posttestdesign the authors demonstrate that portfolio-based learning environments do not change the student's assessment preferences and do not lead to a deeper level of learning. Surprisingly, the results showed a significant increase in the use of surface approaches to learning. One of the explanations put forward by the authors is that students may not have been sufficiently motivated to invest sufficient time and energy in their portfolios. Moreover, students preferred a "closed-book" examination, which is the traditional form of assessment at most Belgian Universities. We concur with the authors' explanations for their findings, especially since we are dealing here with first-year students who are not very familiar with alternative forms of assessment and have proven to be successful with traditional forms of assessment—so why change? Given this relatively long "traditional" background of the students, one might argue that the intervention may have been too short (i.e., one semester) to be successful. Therefore, it would be very interesting in a future study to expose students for a longer period of time to a portfolio-based learning environment and see whether it leads to a deeper level of learning.

Another interesting study done by researchers from the University of Antwerp addresses a similar issue. Gijbels and colleagues (this issue) investigated change in students' learning approaches and in their perception of assessment in a constructivist learning environment. In line with the results found by their colleagues, they showed that although students change their perception of assessment towards more deep level demands, they did not change their actual approach to learning towards a deeper approach. Even worse, students seem to have developed more surface approaches towards learning during the course. To account for their findings the authors concur with the explanations mentioned above in that deep learning leads to a high workload and may result in feelings of stress (Entwistle and Ramsden 1983; Trigwell and Prosser 1991). Also, the duration of the manipulation (7 weeks) may have been too short for effects of this learning environment to become visible; students do not change their approach overnight. That is, a manipulation within a 
course is often not sufficient to change students' behavior when that behavior has been conditioned over many years. This is not only true for students. Educators may also (unwittingly) reinforce surface approaches towards learning.

Using the Model of Domain Learning (MDL; Alexander 1997, 2003) as their theoretical framework, Dinsmore and colleagues (this issue) investigated the effects of students' participation in a collaborative, project-based engineering design course on their interests and knowledge (declarative, procedural, and principled). The authors address an important, and often ignored, issue in their paper by emphasizing the distinction between the where, the who, the what, and the when of learning. That is, many studies that investigate the effectiveness of (new) learning environments tend to ignore one or more of these dimensions. This distinction reminded us of a very popular book by Donald Norman "The design of everyday things" that had a great impact on human factors research (Norman 1988). One of the problems that he discusses in his book is about a designer, for instance of a camera, who introduces many different kinds of functions and controls that may be interesting for an advanced photographer but are completely irrelevant (or even annoying) for an average user (i.e., the majority of users). Similarly, a learning environment may not be very effective, not because there is a problem with the instructional format (i.e., the where), but simply because the content (i.e., the what) is too difficult given the students' expertise level (i.e., who). Contrary to their expectations, the authors show that although there is some gain in declarative knowledge, other types of knowledge and personal interest do not change during the course. In line with both studies from the University of Antwerp, we cannot exclude the possibility that a period of one semester/course may have been too short to bear fruits for the students.

Developing good writing skills is an extremely important quality in our society because it enables us to communicate with others, provides us with opportunities to express ourselves, and to share our thoughts and ideas with others. One may even argue that, since the introduction of the computer and the Internet, good writing skills have become even more important in our society. Harris, Graham and colleagues have played a prominent role in optimizing strategies to improve students' writing skills (e.g., Graham and Harris 1994; Harris and Graham 1985, 1992, 1999). Their paper for this special issue provides an overview of their research on Self-Regulated Strategy Development (SRSD). A lot empirical evidence has been gathered and SRSD has proven to be an important contribution to teachers' instructional techniques. As has been outlined above and in the paper by Loyens and Gijbels (this issue), it is not easy to define a constructivist learning environment, and some may even argue that SRSD should not be considered a constructivist learning environment. However, we concur with the authors pragmatic approach: "We believe advocates of NLEs (New Learning Environments) should consider the literature and research base indicating effective instruction is not based on a forced dichotomy between theoretical perspectives, but a thoughtful, pragmatic blending of practices based on evidence gained from various perspectives and lines of research" (Harris, Santangelo, and Graham, this issue). The only thing that we missed in their overview on writing research was a discussion about the opportunities that new technology has to offer and the implications this may have for future teaching strategies.

The study by Loyens and colleagues (this issue) investigated constructivist learning environments from a students' perspective and focused on instructional conceptions of learning. More specifically, relationships between those conceptions of constructivist learning and students' regulation and processing activities were examined. Their results indicated several structural relationships between conceptions of constructivist learning on the one hand, and regulation and processing strategies of both the Inventory of Learning 
Styles (Vermunt 1992) as well as the Motivated Strategies for Learning Questionnaire (Pintrich and de Groot 1990). Self-report questionnaires were used in this study and, in discussing the results of their research, the authors address the need for measures that capture behaviors. We believe this is a pivotal point. Studies using both quantitative as well as qualitative methods (e.g., interviews, observations, etc.) could broaden our understanding of prominent concepts in educational research such as self-regulated learning. Another issue that emerged from this article was the discrepancy between conceptions of self-regulated learning and actual self-regulated learning activities. Results showed that students disagreed with statements about self-regulated learning (i.e., mean scores were negative). In contrast, the same students reported higher use of self-regulated learning activities, compared to a norm group. This is a reassuring finding since even though students seem to prefer external regulation by, for example, the teacher, it does not stop them engaging in self-regulated learning activities. But this finding also shows that relationships between conceptions or beliefs and learning activities are not always clear-cut. Furthermore, significant relationships were found between self-regulation and deep and concrete processing, which could be expected based on the learning patterns that Vermunt (1992) defined. However, self-regulation did also show a moderate relationship with stepwise processing, which is characterized by memorization and rehearsal. The authors explain that memorization may be used at some stage of the learning process, for certain purposes or in certain subject areas. Hence, deep processing does not necessarily exclude stepwise processing. We agree with this explanation, which also mirrors the ideas that Harris and colleagues (this issue) put forward in their plea for combining the best of different worlds for instruction.

The studies reported in this special issue are good examples of current research on constructivist learning environments, but they also illustrate the difficulties faced by research in this area. That is, the studies demonstrate how difficult it is to investigate the effectiveness of these environments because so many factors seem to be involved and they are often difficult to control. This is also reflected in the fact that several studies in this special issue do not find, or only partly find, the results they anticipated. In spite of all the intricacies associated with this type of research, we would like to commend the authors for their courageous efforts to provide us with a better understanding of the effects of constructivist learning environments and we hope that their research will inspire others, which is necessary to help us to create more optimal learning environments for our students.

Acknowledgment We would like to thank Sofie Loyens, David Gijbels, and Peter Goodyear for the invitation to write this discussion article and their valuable comments on an earlier draft.

Open Access This article is distributed under the terms of the Creative Commons Attribution Noncommercial License which permits any noncommercial use, distribution, and reproduction in any medium, provided the original author(s) and source are credited.

\section{References}

Alexander, P. A. (1997). Mapping the multidimensional nature of domain learning: The interplay of cognitive, motivational, and strategic forces. In M. L. Maehr \& P. R. Pintrich (Eds.), Advances in motivation and achievement (Vol. 10, pp. 213-250). Greenwich, CT: JAI Press.

Alexander, P. A. (2003). The development of expertise: The journey from acclimation to proficiency. Educational Researcher, 32, 10-14.

Entwistle, N., \& Ramsden, P. (1983). Understanding student learning. London: Croom Helm. 
Gijbels, D., \& Dochy, F. (2006). Students' assessment preferences and approaches to learning: Can formative assessment make a difference? Educational Studies, 32, 401-411.

Graham, S., \& Harris, K. R. (1994). The role and development of self-regulation in the writing process. In D. Schunk \& B. Zimmerman (Eds.), Self-regulation of learning and performance: Issues and educational applications (pp. 203-228). New York: Lawrence Erlbaum.

Harris, K. R., \& Alexander, P. A. (1998). Integrated, constructivist education: Challenge and reality. Educational Psychology Review, 10, 115-127.

Harris, K. R., \& Graham, S. (1985). Improving learning disabled students' composition skills: Self-control strategy training. Learning Disability Quarterly, 8, 27-36.

Harris, K. R., \& Graham, S. (1992). Self-regulated strategy development: A part of the writing process. In M. Pressley, K. R. Harris \& J. Guthrie (Eds.), Promoting academic competence and literacy in school (pp. 277-309). New York: Academic Press.

Harris, K. R., \& Graham, S. (1999). Programmatic intervention research: Illustrations from the evolution of self-regulated strategy development. Learning Disability Quarterly, 22, 251-262.

Norman, D. A. (1988). The design of everyday things. New York: Doubleday Publishing Group.

Pintrich, P. R., \& de Groot, E. V. (1990). Motivational and self-regulated learning components of classroom academic performance. Journal of Educational Psychology, 82, 33-40.

Trigwell, K., \& Prosser, M. (1991). Relating approaches to study and quality of learning outcomes at the course level. British Journal of Educational Psychology, 61, 265-275.

Vermunt, J. D. H. M. (1992). Leerstijlen en sturen van leerprocessen in het hoger onderwij-naar procesgerichte instructie in zelfstandig denken [Learning styles and regulation of learning in higher education-towards process-oriented instruction in autonomous thinking]. Amsterdam/Lisse: Swets \& Zeitlinger. 